\section{$\underset{\substack{\text { hommes } \\ \text { \& migrations }}}{ }$}

\section{Hommes \& migrations}

Revue française de référence sur les dynamiques

migratoires

$1283 \mid 2010$

Cuisines et dépendances

\title{
À la table des migrants
}

\section{Marie Poinsot}

\section{CpenEdition \\ Journals}

\section{Édition électronique}

URL : http://journals.openedition.org/hommesmigrations/982

DOI : 10.4000/hommesmigrations.982

ISSN : 2262-3353

\section{Éditeur}

Musée national de l'histoire de l'immigration

\section{Édition imprimée}

Date de publication : 1 janvier 2010

Pagination : 1

ISBN : 978-2-919040-04-9

ISSN : $1142-852 X$

\section{Référence électronique}

Marie Poinsot, «À la table des migrants », Hommes \& migrations [En ligne], 1283 | 2010, mis en ligne le 29 mai 2013, consulté le 22 septembre 2020. URL : http://journals.openedition.org/ hommesmigrations/982 ; DOI : https://doi.org/10.4000/hommesmigrations.982 


\section{À la table des migrants \\ Par Marie Poinsot, rédactrice en chef}

Les migrations ne se limitent pas aux mouvements de population. Quand ils le peuvent, les migrants prennent dans leurs bagages des denrées, des ustensiles de cuisine, des recettes ; dès qu'ils le peuvent, ils transplantent dans la société d'installation leurs pratiques alimentaires, dont les modalités varient selon les contextes. Si manger et boire sont des actes quotidiens vitaux pour tout un chacun, ils revêtent pour les migrants une fonction supplémentaire : celle d'être un trait d'union entre leur pays d'origine et celui où ils vivent désormais. La présence de compatriotes et les stratégies commerciales dans certains secteurs alimentaires comme la restauration leur permettent de conserver leur patrimoine culinaire en le faisant découvrir aux autres. Manger n'est plus seulement se nourrir, mais aussi transmettre aux plus jeunes et partager le repas avec les autres : en famille, avec des amis ou en dehors du cercle intime. L'ensemble de ces pratiques, objets et savoir-faire constitue une partie de ce patrimoine, que pourtant peu de travaux sur l'immigration prennent en compte comme un thème central d'étude. Les enjeux autour de l'alimentation dépassent la seule dimension pratique pour recouvrir une valeur symbolique et identitaire déterminante. Ils traduisent aussi l'état des relations entre les migrants, leur pays d'origine et les générations suivantes.

La préparation des plats, l'art de les présenter et de les servir sont agrémentés par celui d'être à table, de recevoir, de discuter. Les mets et les mots se combinent ainsi pour tisser une relation moins distante avec les autres. Le repas devient l'espace de l'hospitalité et du partage. Moments toujours plus rares et privilégiés aujourd'hui, où la malbouffe et les repas express gagnent du terrain sur la convivialité.

L'ouverture au monde passe donc par la découverte de la cuisine des autres, initiation chaque fois renouvelée à des saveurs, des arômes et des couleurs que l'on ne connaît pas. Quand il devient gastronomie, l'art culinaire alerte les sens et mobilise les sensations au service d'une diplomatie culturelle de haut niveau. En revanche, certaines cuisines ont migré avec succès et fulgurance dans le monde entier en devenant des standards internationaux de l'alimentation rapide et économique. Pizza, hamburger, kebab, sushi affirment partout leur forte capacité intrusive et d'adaptation aux codes culinaires environnants. La visibilité ou l'invisibilité de ces différentes cuisines attestent donc de la place des migrants dans nos sociétés.

Grâce à un appel à contribution lancé en 2009 sur la relation entre migrations, pratiques alimentaires et échanges culinaires, la revue Hommes et Migrations publie dans ce dossier une sélection d'articles qui abordent ces thèmes à partir de travaux universitaires menés dans plusieurs pays et sur différentes populations, en privilégiant les approches pluridisciplinaires. Nous vous en souhaitons une bonne dégustation. 